\title{
Ethik in der Medizin
}

\section{Gefährdet die Ökonomisierung das ärztliche Berufsethos?}

\author{
Wie gefährdet ist das ärztliche Berufsethos durch die zunehmende \\ Ökonomisierung der Medizin? Und wie gelingt es Ärzten, mit dem \\ wachsenden ökonomischen Druck im Arbeitsalltag umzugehen? Diese \\ Fragen erörterte der Philosoph Prof. Dr. Dr. Julian Nida-Rümelin von \\ der Ludwig-Maximilians-Universität in München zwar beim Eröffungs- \\ vortrag des Internistenkongresses. Sie betreffen aber jenseits von \\ Fachgrenzen alle Ärzte.
}

$\mathrm{D}$ as Arzt-Patient-Verhältnis sei, ob man es will oder nicht, ein Vertrauensverhältnis, sagte NidaRümelin und stellte klar: „Wenn ich davon ausgehe, dass der Arzt mir immer das empfiehlt, was ihm den größten Nutzen bringt, ist dieses Vertrauensverhältnis zerstört." Zerstörtes Vertrauen könne sich durchaus auch in der Beziehung etwa zwischen Kunden und einem KfzMechaniker entwickeln. Bei genauerer Betrachtung sei die Situation aber keinesfalls deckungsgleich. Mit Blick auf das Arzt-Patient-Verhältnis habe Vertrauen eine existenzielle Dimension.

\section{Kaum vereinbare Normen}

Eine umfassende Ökonomisierung sei unvereinbar mit den medizinischen Normen und Bedingungen medizinischer Praxis. „Man kann den einzelnen Arzt nicht zum Erfüllungsgehilfen ökonomischer Optimierungsstrategien machen", betonte Nida-Rümelin. Ärzten wünsche er folgende Einsicht: „Wir handeln vernünftig, wir setzen Ressourcen sparsam und nicht leichtfertig ein, wir verschwenden sie nicht. Wir kommunizieren mit Patienten wahrhaftig und vertrauensvoll.“ Ärzte seien nicht lediglich Vertragspartner mit Rechtsanwälten im Hintergrund, die auf Fehler lauern. Ziel sei eine gesündere, bessere und humanere Welt: „Auf diesem Weg kommen wir nicht voran ohne Vertrauensvorschuss,

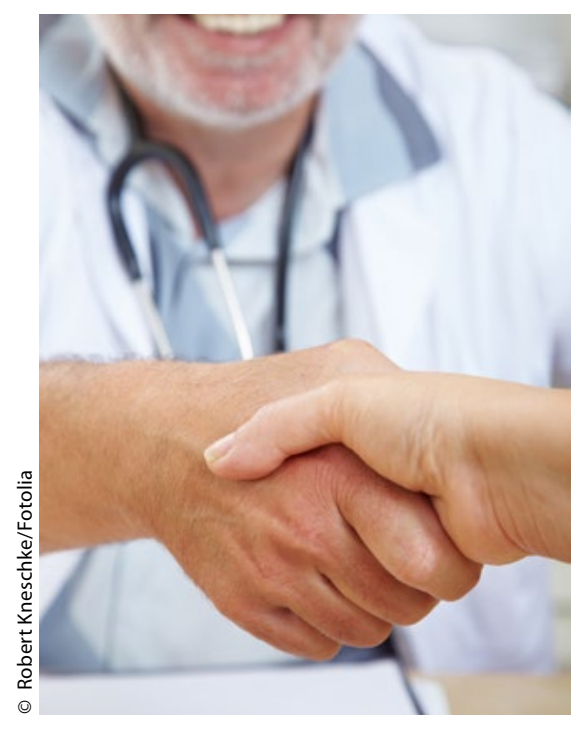

Vertrauen ist die Basis für eine funktionierende Beziehung zwischen Arzt und Patient.

Berufsethos und eine ökonomische Praxis, die eingebettet bleibt in Strukturen von Kooperation und Vertrauen“, erläuterte der Philosoph.

Die Endokrinologin Prof. Petra-Maria Schumm-Draeger vom Klinikum Bogenhausen in München stellte ergänzend klar, dass der Patient aus vielerlei Gründen das Produkt medizinischer Hilfe nicht frei wählen und erwerben könne wie ein Kleidungsstück: „Der Patient ist mehr als nur ein Konsument!“
Wenn die Indikationsstellung für Diagnostik und Therapie aus ökonomischen Gründen optimiert werde, komme es zu einem fundamental gestörten Vertrauensverhältnis zwischen Arzt und Patient. Im schlimmsten Fall könnten eine optimierte Diagnose und Behandlung zur Fehldiagnose und Fehlbehandlung werden, die den Patienten schädigten.

Im Gespräch mit Springer Medizin konstatierte die Münchner Internistin und diesjährige Präsidentin des DGIMKongresses: „Ökonomische Kennziffern verdrängen unsere ethischen Grundsätze: Überlegungen zur Indikation medizinischer Maßnahmen werden zunehmend von Kenngrößen bestimmt, die sich eben nicht primär nach dem individuellen Bedarf des Patienten richten, sondern nach dessen Wertigkeit im Abrechnungssystem. An vielen Stellen fehlt Zeit für bestimmte Aktivitäten, vor allem in der sprechenden Medizin wie beispielsweise für Präventionsarbeit und Aufklärung. All dies wirkt sich auf die Qualität der Versorgung aus.“

\section{Ärzte sind keine Kaufleute}

„Wir Ärzte haben nichts gegen Ökonomie in der Medizin, wohl aber gegen Merkantilismus," sagte der Präsident der Bundesärztekammer Prof. Frank-Ulrich Montgomery, „das ist das Problem, das wir beackern müssen. “ Letztlich ist der Arzt in unserem ökonomisch dominierten System der wichtigste Garant für die individuelle Patientenversorgung, glaubt der Chef des Berufsverbands Deutscher Internisten Dr. Hans-Friedrich Spies. „Er ist ein Qualitätsparameter erster Ordnung. Er allein ist durch seine Berufsordnung verpflichtet, seine Entscheidung am Patienten auch ohne wirtschaftliche Beeinflussung zu treffen und hat die Entscheidung direkt dem $\mathrm{Pa}$ tienten zu vermitteln." Christoph Fuhr 